\title{
Comparison of Two Simplified Approaches for Ground Temperature Estimations in Australia
}

\author{
Lu Xing Cuncun Mao Zhou Yu Olga Mikhaylova Pingfang Hu
}

\begin{abstract}
Developing an accurate and practical method for ground temperature estimations are critical for the ground source heat pump system design and energy calculation procedures. In Australia, Baggs' method is a common procedure for ground temperatures predictions as a function of depth and time of year. Xing and Spitler developed a new procedure for ground temperature estimations for engineering applications at 4112 sites worldwide. This new procedure considers the variations of surface cover conditions (bare soil, vegetated, asphalt or concrete), effects of snow cover and soil freezing or melting. These important factors, which significantly affect the ground temperature results accuracy either are neglected or are simplified in Baggs' method. In this paper, we selected 6 sites in Australia which belongs to two climates: warm climates and arid or dry summer climates. Xing and Spitler's method and Baggs' method are used respectively to calculate the ground temperatures at depths of $10 \mathrm{~cm}, 20 \mathrm{~cm}$, $50 \mathrm{~cm}$ and $100 \mathrm{~cm}$. Calculation results of two methods are both compared to the 3-14 years of measurement results at the 6 sites and validation results are discussed and investigated. Results demonstrate the Xing and Spitler's method averaged root mean square error (RMSE) is $2.2^{\circ} \mathrm{C}$ of the 6 sites; Baggs' method averaged RMSE is $3.4^{\circ} \mathrm{C}$ of the 6 sites. This paper presents a new and improved procedure for ground temperature estimations in Australia. It enables a more accurate design of the ground heat exchangers so as to reduce the capital cost of the installed ground source beat pump systems.
\end{abstract}

Key words: Ground source heat pump system Ground temperatures World wide dataset

\section{INTRODUCTION}

Estimations of undisturbed ground temperatures are quite important and are required in building design load calculations, building energy calculations, ground heat exchangers design and energy analyses of district heating and cooling systems. As house envelopes become better insulated and tighter, the heat transfer to/from the foundation becomes more important. Although losses to the ground are currently neglected for cooling load calculations, it is possible Dr. Lu Xing (lxing@hust.edu.cn) is an assistant professor of Energy \& Power Engineering; Prof. Pingfang Hu (pingfanghu@hust.edu.cn) is of Environmental Science \& Engineering, Huazhong University of Sci. \& Tech., China Dr. Olga Mikhalova (olga.mikhaylova@unimelb.edu.au) is a research fellow of Geotechnical Engineering, University of Melbourne, Australia 
that it will be advantageous to include the heat loss in the future. Beyond foundation heat transfer, undisturbed ground temperatures are also used in the design of vertical and horizontal ground heat exchangers and district heating and cooling systems.

Although the soil temperature predictions in the subsurface are of great importance for design of ground heat exchangers in the GSHP system, soil temperature data available for engineering applications are limited. There are two types of approaches used for estimating ground temperature: numerical method and analytical method. Numerical models account for such phenomena such as moisture transport, soil freezing or melting, snow cover at the ground surface, but these models are computationally intensive and time consuming. Analytical models require less computational time and are thus more convenient for engineering applications.

In the United States, the commonly used analytical approach is the one-harmonic model first proposed by Fourier (1822, as cited by Narasimhan 2010). The model relies on three parameters - annual average ground temperature, annual amplitude of ground temperature at the surface and the phase angle to estimate the ground temperatures. The average undisturbed ground temperature and annual amplitude of surface temperature variation are read from very small maps for the continental US (Figure 17 of Chapter 34 of the 2011 ASHRAE Handbook HVAC Applications) or North America (Figure 13 of Chapter 18 of the 2013 ASHRAE Handbook - Fundamentals). ASHRAE published a district heating manual (ASHRAE 2013b) which also uses one-harmonic model to estimate the undisturbed ground temperatures. This is done for all 5564 weather stations world-wide listed in Chapter 14 of 2009 ASHRAE Handbook - Fundamentals. More details of the commonly used method in the U.S. are given in Xing and Spitler (2016b).

Xing and Spitler developed a new procedure - two harmonic model for ground temperature estimations at 4112 stations world-wide (Xing et al. 2016). The model mainly depends on five parameters: annual average ground temperature, two temperature amplitude, two phase lags. Xing and Spitler utilized world-wide measured weather data and a numerical model to calculate ground temperatures; the calculated results are used for generating the five parameters of the two harmonic model. The new procedure considers various surface cover conditions, such as asphalt, concrete, vegetated, etc. It considers snow cover and soil freezing or melting effects.

We used Xing and Spitler procedure, ASHRAE Handbook procedure and ASHRAE district heating manual procedure to predict ground temperatures at 19 sites located in three climates in the U.S.: warm climates, snow climates and arid or dry summer climates. The predicted ground temperatures are compared to the measured results; mean root mean square error (RMSEs) of 19 sites are summarized. It is found that the using Xing and Spitler procedure is $1.4^{\circ} \mathrm{C}$, ASHRAE Handbook procedure and ASHRAE district heating manual procedure RMSEs are $2.6^{\circ} \mathrm{C}$ and $2.5^{\circ} \mathrm{C}$ respectively. The study results of the 19 sites in the U.S. shows that previous ASHRAE procedures work well in warm climates, the model accuracy obviously drops in the cold climates and arid or dry summer climates. 
In order to demonstrate the undisturbed ground temperature estimations is a key factor which greatly affects the design length of the ground heat exchanger piping in the in ground source heat pump (GSHP) systems, consequently, the system cost. Xing et al. (2017) presents the impact of Xing and Spitler model development on the horizontal ground heat exchanger (HGHX) design. 12 geographically diverse sites in United States with three different HGHX configurations were studied. For each site, HGHX design length using the Xing and Spitler model estimated ground temperatures as inputs are compared to design results based on measured ground temperatures; the calculated HGHX design length percentage error are within $\pm 18.9 \%$. The calculated HGHX design length percentage error using previous common methods for ground temperature estimations in United States are much higher which are within $\pm 38.3 \%$ and $\pm 57.7 \%$ respectively.

Since ground temperature estimations are critical for design of ground heat exchangers in the GSHP systems, in this paper, we studied the widely applied model of ground temperature prediction in Australia - Baggs' model (1982) and compared it to Xing and Spitler method. The Baggs' formula depends on 3 parameters: annual average ground temperature, the soil surface temperature amplitude, and the phase angle. To obtain the annual average ground temperature, Baggs developed a map that shows the geographical distribution of a temperature differential which relates annual average ground temperature to annual average air temperature. The map was developed which used long-term ground temperature records from 20 sample sites scattered throughout 5 states of Australia. Baggs' method assumes the ground is either bare soil or covered by vegetation, it doesn't consider other ground surface conditions such as covered by concrete or asphalt etc. It neglects the snow cover, rainfall and soil freezing and melting effects and assumes there is a simplified differential correlation between the ground temperatures and the air temperatures.

Both Xing and Spitler's method and Baggs' method are developed procedures for ground temperature estimations; Baggs' method is built based on more simplified assumptions than Xing and Spitler's method. In this paper, we evaluated two methods' performances basesd on case study results. 6 sites located in 2 climates: arid or dry summer climates and warm climates in Australia are chosen for the case study. The soil temperatures at depths of $10 \mathrm{~cm}, 20 \mathrm{~cm}, 50 \mathrm{~cm}$ and $100 \mathrm{~cm}$ are calculated respectively using the Xing and Spitler's method and Baggs' method. The results were compared with the 3-14 year measurements at the 6 sites to analyze the accuracy of the two methods.

\section{METHODOLOGIES}

6 sites in Australia have been chosen for the parametric study. These sites belong to 2 climates: warm climates and arid or dry summer climates. The geographical names and climate zones of the chosen sites are shown in Table 1, the geographical locations are shown in Figure 1. 
Measured weather data and measured ground temperature data are obtained from the Australian Bureau of Meteorology website: http://www.bom.gov.au. There are 284 temperature-monitoring sites, these data have been screened according to the different monitoring quality of each site (monitoring duration, monitoring frequency, monitoring accuracy, monitoring depth) and 6 sites are finally chosen.

Table 1. Six Parametric Study Sites in Australia

\begin{tabular}{ccccc}
$\begin{array}{c}\text { Climate } \\
\text { zone }\end{array}$ & States & Site name & $\begin{array}{c}\text { Köppen-Geiger } \\
\text { Climate type }\end{array}$ & $\begin{array}{c}\text { Latitude and longitude } \\
\left({ }^{\circ},{ }^{\circ}\right)\end{array}$ \\
\hline \hline \multirow{2}{*}{ Arid or dry } & Queensland & Longreach aero & Bsh & $-23.43,144.28$ \\
summer & Western & Geraldton airport & Csa & -28.80 .114 .70 \\
climates & Australia & Perth airport & Csa & $-31.93,115.95$ \\
& South Australia & Adelaide (Kent town) & Csb & $-34.92,138.62$ \\
\hline \multirow{2}{*}{ Warm } & New South & Wagga wagga amo & Cfa & $-35.17,147.45$ \\
climates & Wales & Canberra airport & Cfb & $-35.30,149.20$ \\
\hline
\end{tabular}

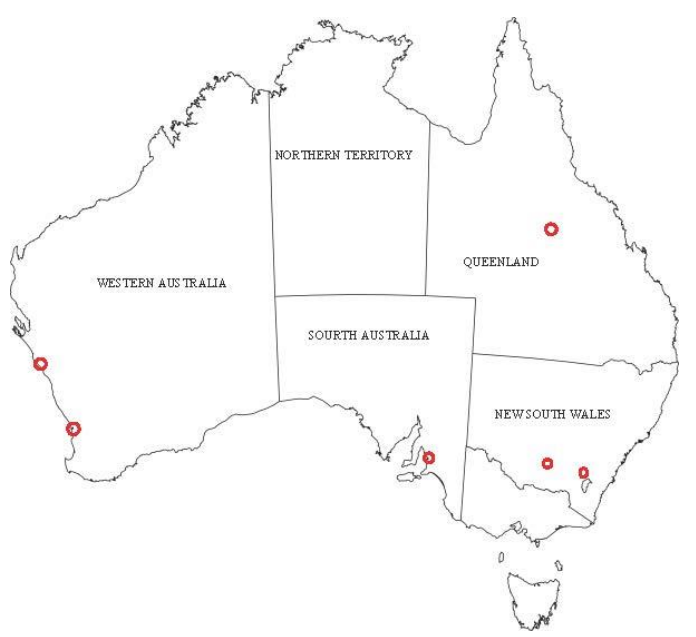

Figure 1 Six parametric study sites in Australia

\section{Xing and Spitler's method}

Xing and Spitler developed a two-harmonic analytical model that considers variations of ground cover conditions, the effects of snow cover, soil freezing and melting. The model depends on five parameters: annual average ground temperature, two temperature amplitudes, two phase lags. In Equation 1, these five parameter values are estimated using the computed results from a numerical model (Xing and Spitler 2016a, Xing and Spitler 2016b, Xing et al. 2016). The inputs to the numerical models are weather files including air temperatures, solar radiation, relative humidity, wind speed, rainfall, dew point temperature:

$$
T_{\mathrm{S}}(z, \quad t)=T_{\mathrm{s}, \text { avg }}-\sum_{n=1}^{2} e^{-z \sqrt{\frac{n \pi}{\alpha_{s} t_{p}}}} \cdot T_{\mathrm{s}, \text { amplitude }, n} \cos \left[\frac{2 \pi n}{t_{p}}\left(t-P L_{n}\right)-z \sqrt{\frac{n \pi}{\alpha_{s} t_{p}}}\right]
$$

Where: 
$T_{\mathrm{S}}(z, t)$ is the undisturbed soil temperature at the depth of and time of the year, in ${ }^{\circ} \mathrm{C}$ or ${ }^{\circ} \mathrm{F}$;

$z$ is the soil depth, in $\mathrm{m}$ or $\mathrm{ft}$;

$t$ is the time of year, starting from January 1st, in days;

$t_{p}$ is the period of soil temperature cycle (365), in days;

$\alpha_{\mathrm{s}}$ is the soil diffusivity, in $\mathrm{m} 2 /$ day or $\mathrm{ft} 2 /$ day;

$T_{\mathrm{s} \text {,avg }}$ is the annual average ground temperature, in ${ }^{\circ} \mathrm{C}$ or ${ }^{\circ} \mathrm{F}$;

$T_{\mathrm{s}, \text { amplitude, } n}$ is the $\mathrm{nth}$ order temperature amplitude, when $\mathrm{n}=1$, it is the annual temperature amplitude at the ground surface, equal to half of the difference between the maximum and minimum monthly average temperatures at the ground surface in a year, in ${ }^{\circ} \mathrm{C}$ or ${ }^{\circ} \mathrm{F}$;

$P L_{n}$ is the nth phase lag of the ground temperature cycle, in days.

\section{Baggs' method}

Baggs revised the Labs's model for ground temperature estimations (1982) by considering the variation of vegetation covers into the model, as shown in Equation 2. Equation 2 relies on five parameters $k_{v}, T_{a, \text { avg }}, \Delta T_{\mathrm{s}, \mathrm{a}}, T_{\mathrm{a} \text {,amplitude, } 1}$ and $P L_{1}$ to predict ground temperatures. Baggs found that at 10 meters depth, there was a certain mathematical relationship between annual average ground temperature and annual average air temperature. He presented a map for $\Delta T_{s, a}$ according to the data of 20 sample sites scattered throughout 5 states of Australia:

$$
\begin{aligned}
& T_{\mathrm{S}}(z, \quad t)=\left(T_{\mathrm{a}, \mathrm{avg}} \pm \Delta T_{\mathrm{s}, \mathrm{a}}\right)+1.07 k_{v} T_{\mathrm{a}, \text { amplitude }, 1} e^{-0.00316 z \sqrt{\frac{1}{\alpha_{s}}} \times} \\
& \cos \left[\frac{2 \pi}{365}\left(t-P L_{1}-0.1834 z \sqrt{\frac{1}{\alpha_{s}}}\right)\right]
\end{aligned}
$$

Where:

$\Delta T_{\mathrm{s}, \mathrm{a}}$ is the difference of annual average ground temperature and annual average air temperature, in ${ }^{\circ} \mathrm{C}$ or ${ }^{\circ} \mathrm{F}$;

$T_{\mathrm{a}, \mathrm{avg}} \pm \Delta T_{\mathrm{s}, \mathrm{a}}$ is the annual average ground temperature, in ${ }^{\circ} \mathrm{C}$;

$k_{v}$ is the vegetation coefficient, $k_{v}=1$ for bare ground, $k_{v}=0.22$ for year-round full vegetation cover;

$T_{\mathrm{a}, \text { amplitude, } 1}$ is the half of difference of the maximum monthly average air temperature and the minimum monthly average air temperature, in $\mathrm{K}$ or ${ }^{\circ} \mathrm{F}$;

$P L_{1}$ is the phase of air temperature wave, number of days in which the annual maximum air temperature, in days.

\section{RESULTS AND DISCUSSION}

The five Xing and Spitler' method parameters: annual average soil surface temperature, two temperature amplitudes and two phase angles for the six sites are presented in Table 2 . The 
five Baggs' method parameters are shown in Table 3.

Xing and Spitler's model results and Baggs' model results at the depths of $10 \mathrm{~cm}, 20 \mathrm{~cm}$, $50 \mathrm{~cm}$ and $100 \mathrm{~cm}$ are calculated. The calculated results are compared with the measured ground temperatures of 3-14 years in 6 sites, model RMSEs at $10 \mathrm{~cm}, 100 \mathrm{~cm}$ and averaged model RMSEs of four depths are calculated and presented in Figures 2, 3 and 4. The RMSE results are grouped into two climates: arid or dry summer climates, warm climates. Results demonstrate the Xing and Spitler's method averaged RMSE is $2.2^{\circ} \mathrm{C}$ of the 6 sites; Baggs' method averaged RMSE is $3.4^{\circ} \mathrm{C}$ of the 6 sites.

Table 2. Xing and Spitler' Method Parameters

\begin{tabular}{ccccccc}
\hline $\begin{array}{c}\text { Climate } \\
\text { zone }\end{array}$ & Site & $\begin{array}{c}\boldsymbol{T}_{\text {s,avg }} \\
\left({ }^{\circ} \mathbf{C}\right)\end{array}$ & $\begin{array}{c}\boldsymbol{T}_{\text {s,amplitude, }} \\
\left({ }^{\circ} \mathbf{C}\right)\end{array}$ & $\begin{array}{c}\boldsymbol{P L}_{1} \\
(\text { day })\end{array}$ & $\begin{array}{c}\boldsymbol{T}_{\text {s,amplitude, }} \\
\left({ }^{\circ} \mathbf{C}\right)\end{array}$ & $\begin{array}{c}\boldsymbol{P L}_{2} \\
(\mathbf{d a y})\end{array}$ \\
\hline \hline \multirow{2}{*}{$\begin{array}{c}\text { Arid or } \\
\text { dry }\end{array}$} & Longreach aero & 29.0 & -8.1 & 7.9 & 1.2 & 7.9 \\
$\begin{array}{c}\text { summer } \\
\text { climates }\end{array}$ & Geraldton airport & 23.5 & -6.3 & 23.4 & 0.2 & 34.7 \\
\hline \multirow{2}{*}{$\begin{array}{l}\text { Warm } \\
\text { climates }\end{array}$} & Adelaide (Kent town) & 20.9 & -7.9 & 19.9 & -0.8 & 58.4 \\
\hline
\end{tabular}

Table 3. Baggs' Method Parameters

\begin{tabular}{|c|c|c|c|c|c|c|c|}
\hline \multirow{2}{*}{$\begin{array}{c}\text { Climate } \\
\text { type }\end{array}$} & \multirow{2}{*}{ Site } & \multirow{2}{*}{$\begin{array}{l}T_{\mathrm{s}, \text { avg }} \\
\left({ }^{\circ} \mathrm{C}\right)\end{array}$} & \multirow{2}{*}{$\begin{array}{c}\boldsymbol{T}_{\mathrm{a} \text {,amplitude, } 1} \\
\quad\left({ }^{\circ} \mathrm{C}\right)\end{array}$} & \multirow{2}{*}{$\begin{array}{c}P L_{1} \\
\text { (day) }\end{array}$} & \multicolumn{2}{|c|}{$T \mathrm{~s}, \operatorname{avg}=T_{\mathrm{a}, \mathrm{avg}}+\Delta T_{\mathrm{s}, \mathrm{a}}$} & \multirow{2}{*}{$\boldsymbol{k}_{v}$} \\
\hline & & & & & $\boldsymbol{T}_{\text {a,avg }}$ & $\Delta T_{\mathrm{s}, \mathrm{a}}$ & \\
\hline \multirow{4}{*}{$\begin{array}{l}\text { Arid or } \\
\text { dry } \\
\text { summer } \\
\text { climates }\end{array}$} & Longreach aero & 26.9 & 7.8 & 362.0 & 23.9 & 3.0 & 1.0 \\
\hline & Geraldton airport & 21.7 & 5.5 & 25.0 & 18.2 & 3.5 & 1.0 \\
\hline & Perth airport & 21.5 & 5.5 & 57.0 & 18.0 & 3.5 & 1.0 \\
\hline & Adelaide (Kent town) & 19.5 & 6.5 & 44.0 & 17.0 & 2.5 & 1.0 \\
\hline \multirow{2}{*}{$\begin{array}{l}\text { Warm } \\
\text { climates }\end{array}$} & Wagga wagga amo & 15.9 & 8.3 & 4.0 & 15.1 & 0.8 & 1.0 \\
\hline & Canberra airport & 13.2 & 7.4 & 4.0 & 12.8 & 0.4 & 1.0 \\
\hline
\end{tabular}

As shown in Figure 2, Xing and Spitler model RMSEs at $10 \mathrm{~cm}$ depths are within 1.3-3. $2^{\circ} \mathrm{C}$, Baggs model RMSEs are within $2.4-4.5^{\circ} \mathrm{C}$, about $0.4-2.4^{\circ} \mathrm{C}$ differences in RMSEs for different sites. Xing and Spitler consider variation of vegetation covers, effects of snow cover and soil freezing or melting. Baggs' method is developed based on relatively simplified assumptions. The value of $\Delta T_{\mathrm{s}, \mathrm{a}}$ in the Baggs' formula is semi-empirical. It is read from a map developed only based on the data of 20 sample sites scattered throughout five states of Australia. Moreover, Baggs method relies on the value of $k_{v}$ associated with the given map of $\Delta T_{\mathrm{s}, \mathrm{a}}$, the value is set to 1.0 by default which means the surface coverage of all areas is bare soil, this may cause errors in the calculation results. 


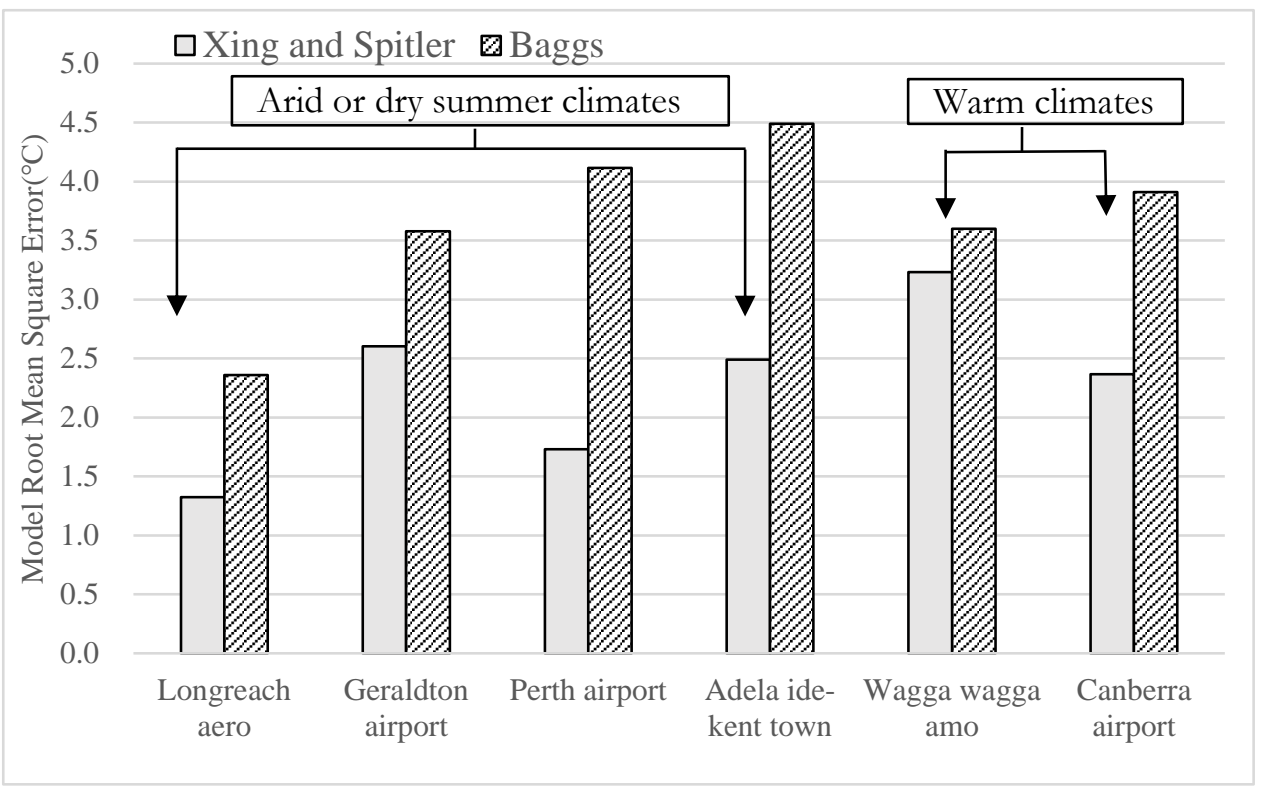

Figure 2 Xing and Spitler's method and Baggs' method RMSEs at 10cm depths for 6 sites

Similar results could be observed in Figures 3 and 4. In Figure 3, Xing and Spitler model RMSEs at $100 \mathrm{~cm}$ depths are within $1.6-3.3^{\circ} \mathrm{C}$, Baggs model RMSEs are within $1.2-3.7^{\circ} \mathrm{C}$, about $0.2-1.7^{\circ} \mathrm{C}$ differences in RMSEs for different sites. In Figure 4, Xing and Spitler model' average RMSEs at 6 sites are within 1.6-3.9 ${ }^{\circ} \mathrm{C}$, Baggs model RMSEs are within 1.8-3.9 ${ }^{\circ} \mathrm{C}$, about $0.2-2.1^{\circ} \mathrm{C}$ differences in RMSEs. There is one site Wagga wagga amo located in New South Wales states and warm climates has a relatively higher RMSEs. We checked the vegetation coverage in the area but found that this does not explain this phenomenon. We speculate that this may be related to the actual surface coverage of the area, such as the length of the local vegetation. More detailed reasons need to be studied later.

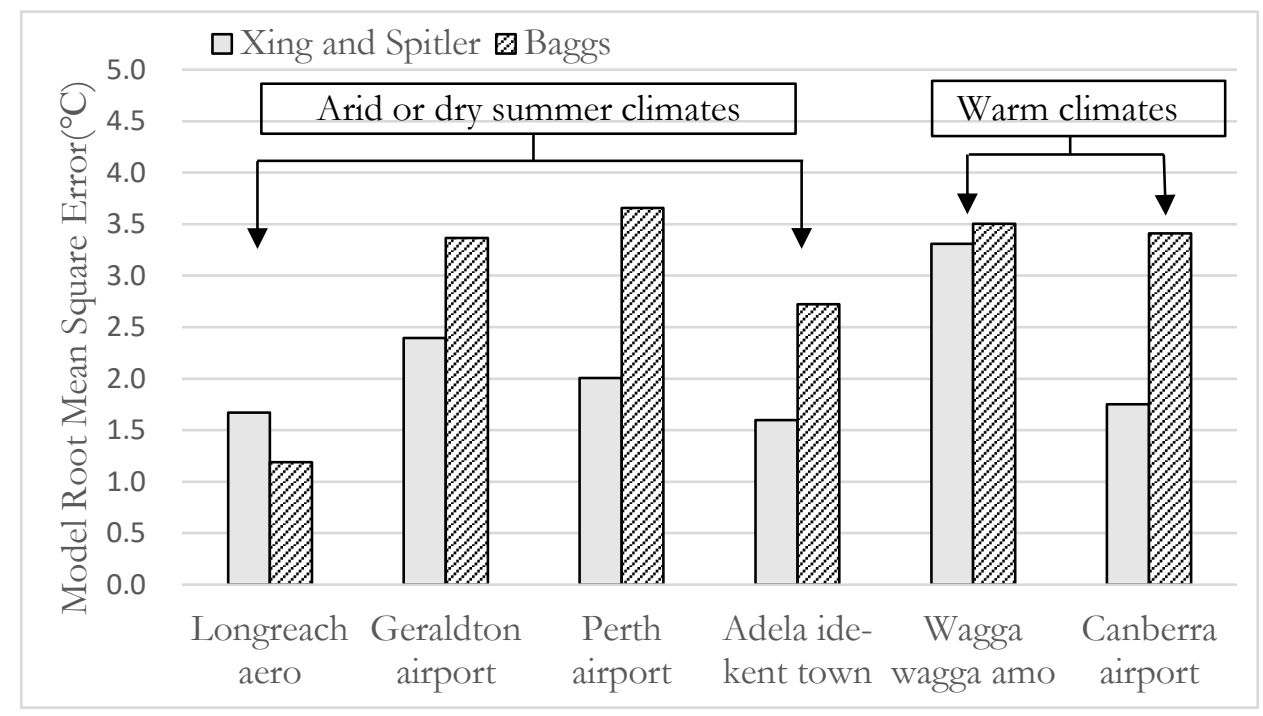

Figure 3 Xing and Spitler's method and Baggs' method RMSEs at $100 \mathrm{~cm}$ depths for 6 sites 


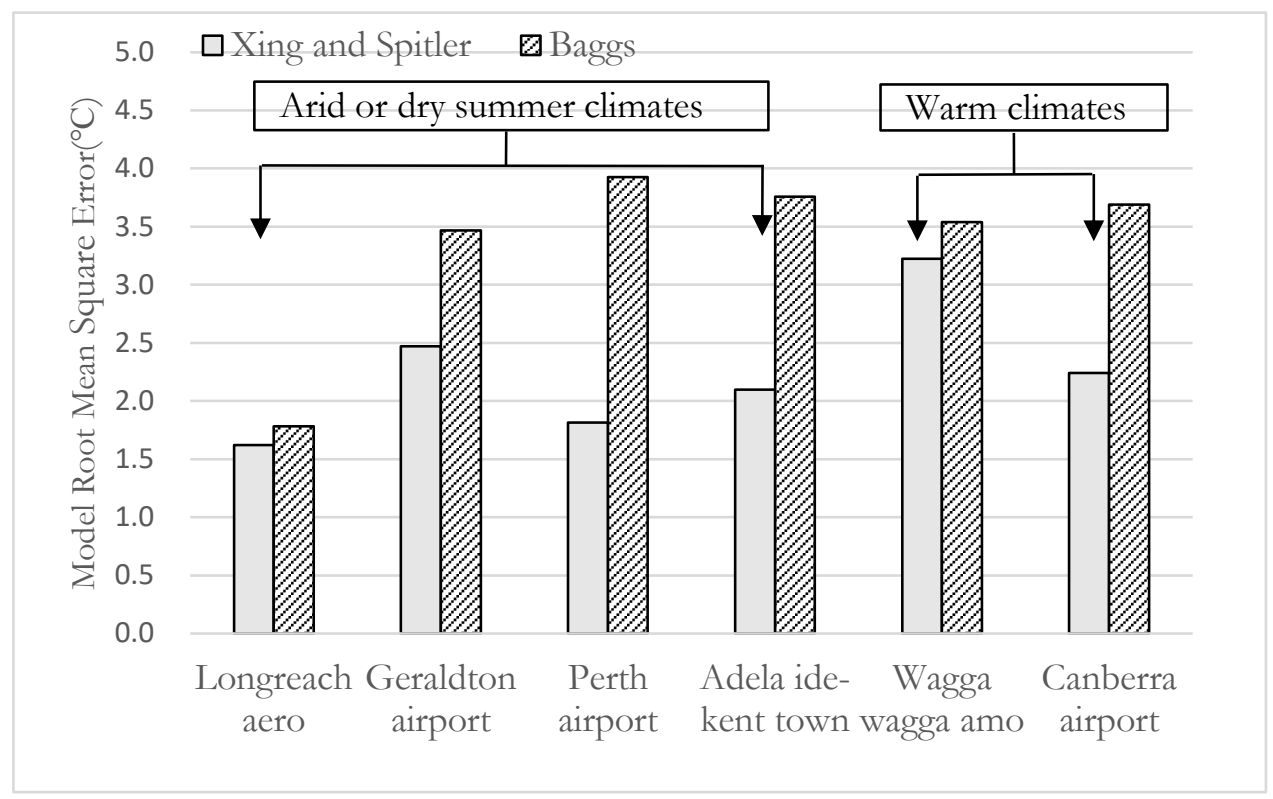

Figure 4 Xing and Spitler's method and Baggs' method averaged RMSEs at four depths for 6 sites

\section{CONCLUSION}

In this paper, two simplified approaches - Xing and Spitler's method, Baggs' method of ground temperatures estimations have been studied. 6 sites located in two climates in Australia: arid or dry summer climates and warm climates have been chosen for the validation and comparison study. The ground temperatures at $10 \mathrm{~cm}, 20 \mathrm{~cm}, 50 \mathrm{~cm}$ and $100 \mathrm{~cm}$ depths are calculated utilizing Xing and Spitler's method and Baggs' method. The simulation results are compared with the measured temperature and RMSEs are summarized. It is found that averaged RMSEs of Xing and Spitler's method at four depths is $2.2^{\circ} \mathrm{C}$ of the 6 sites; averaged RMSEs of Baggs' method at four depths is $3.4^{\circ} \mathrm{C}$ of the 6 sites. The Xing and Spitler's method considers variation of vegetation covers, effects of snow cover and soil freezing or melting. Baggs model is developed based on simplified assumptions. The value of $\Delta T_{\mathrm{s}, \mathrm{a}}$ in the Baggs' formula is semi-empirical, based on a map developed according to the data of 20 sample sites scattered throughout five states of Australia. Moreover, the value of $k_{v}$ associated with the given map of $\Delta T_{\mathrm{s}, \mathrm{a}}$ is set to 1.0 by default which means the surface coverage of all areas is bare soil, this may cause higher errors in the calculation results.

\section{ACKNOWLEDGMENTS}

The authors of this publication gratefully acknowledge Dr. Jeffrey D. Spitler, regent professor from Mechanical and Aerospace Engineering, Oklahoma State University, United States for his support in this research.

\section{REFERENCES}


ASHRAE. 2011. ASHRAE Handbook-Heating Ventilating and Air Conditioning Applications. Atlanta: ASHRAE.

ASHRAE. 2013a. ASHRAE Handbook-Fundamentals. Atlanta: ASHRAE.

ASHRAE. 2013b. District Heating Guide. Atlana: ASHRAE.

Fourier, J. 1822. Theorie Analytique de la Chaleur (print in English in 1878, Analytical Theory of Heat). Paries: Firmin Diot Pere et Fils.

Baggs, S. 1982. Remote Prediction of Ground Temperature in Australian Soils and Mapping its Distribution. Solar Energy. 351-366

Labs, K. 1982. Regional analysis of ground and above-ground climate conclusion. Underground Space 7. 37-65.

Xing, L. and J. D. Spitler. 2016a. Prediction of undisturbed ground temperature using analytical and numerical modeling. Part I : Model development and experimental validation. Science and Technology for the Built Environment. 787-808.

Xing, L. and J. D. Spitler. 2016b. Prediction of undisturbed ground temperature using analytical and numerical modeling. Part II: Methodology for developing a world-wide dataset. Science and Technology for the Built Environment. 809-825.

Xing, L. J. D. Spitler and Arkasama Bandyopadhyay. 2016. Prediction of undisturbed ground temperature using analytical and numerical modeling. Part III: Experimental validation of a world-wide dataset. Science and Technology for the Built Environment. 826-842.

Xing, L., J. D. Spitler, L.H. Li and P.F. Hu. 2016. A model for ground temperature estimations and its impact on horizontal ground heat exchanger design. IGSHPA Technical/Research Conference and Expo Denver March 14-16. 